\title{
Does addition of a diagnostic contrast- enhanced CT to a contemporaneous PET/ CT provide incremental value in patients for restaging of colorectal carcinoma?
}

Kenneth S. K. Yap ${ }^{1 *}$, Ojas H. Mehta ${ }^{4}$, Wing Fai Eddie Lau ${ }^{2,5,6,7}$, Tim Akhurst ${ }^{2,7}$, Satish Warrier ${ }^{3}$, Alexander Heriot ${ }^{3}$ and Rodney J. Hicks ${ }^{2,7}$

\author{
*Correspondence: kenneth.yap@ \\ alfred.org.au \\ ${ }^{1}$ Department of Nuclear Medicine \\ and PET, Level 1, East Block, The \\ Alfred Hospital, Commercial Road, \\ Melbourne, VIC 3004, Australia \\ Full list of author information is \\ available at the end of the article
}

\begin{abstract}
Background: Both constrast-enhanced computed tomography (ceCT) and ${ }^{18}$ F-Fluorodeoxyglucose positron emission tomography (PET) are widely used for evaluation of colorectal cancer. Not infrequently patients undergo both tests, increasing cost and radiation burden. Whether this combination provides useful incremental diagnostic information remains unclear. Our purpose was to determine whether the addition of ceCT to PET/CT results in an appropriate change in the $\mathrm{N}$ or M stage in patients with colorectal cancer.

Methods: This was a single centre, retrospective study in a tertiary referral hospital. Over 9 months, 74 consecutive patients with colorectal carcinoma were referred for PET with a recent ceCT scan and adequate follow-up were analysed. The $\mathrm{N}$ and $\mathrm{M}$ stage of each modality was compared. Management was determined according to institutional guidelines with incremental impact of ceCT results on management categorised as appropriate, inappropriate or unchanged, based on pathological results, clinical or imaging follow-up of discrepant findings.
\end{abstract}

Results: Of 74 patients, PET/CT and ceCT N and M stages were concordant in 56 patients (76\%) but PET/CT and ceCT identified additional abnormalities in 9 cases each respectively. Of the 18 discordant cases, accepting the ceCT result would have appropriately changed management in only 2 patients and inappropriately in 1 with most management plans unchanged. When comparing PET/CT and $\mathrm{ceCT}$, kappa agreement (95\% confidence interval) for $\mathrm{N}$ and $\mathrm{M}$ stage was $0.58(0.20-0.95)$ and $0.60(0.41-0.79)$ respectively reflecting moderate agreement.

Conclusions: Whole-body ceCT probably has limited management impact in colorectal cancer patients who are also undergoing PET/CT and therefore may possibly be omitted from routine use. Targeted regional MRI or ceCT should, however, be considered based on clinical suspicion or when high-resolution anatomical information is required for treatment planning.

Keywords: Colorectal Cancer, PET/CT, Contrast enhanced CT 


\section{Background}

Stand-alone, diagnostic contrast-enhanced computed tomography (ceCT) is a widely-used imaging modality in oncology and represents the current standard of care for staging and restaging colorectal cancer $(\mathrm{CRC}) .{ }^{18} \mathrm{~F}$-Fluorodeoxyglucose positron emission tomography (FDG-PET) is a functional imaging modality increasingly utilised in managing oncology patients. Both modalities can assess potential sites of metastatic spread. In rectal cancer, FDG-PET/CT has been shown to be sensitive for detection of distant metastases (M-stage) (Davey et al., 2008) with fewer false-positive results than $\mathrm{CT}$, especially in the post-treatment setting. In a meta-analysis of restaging of CRC patients, PET has been shown to be more accurate than ceCT (Gambhir et al., 2001) and there is also some evidence that the non-contrast, co-registered CT from PET/CT provides further incremental value towards the interpretation of the FDG-PET study (Kamel et al., 2004).

In our facility, PET/CT is widely used for primary staging, therapeutic response assessment and restaging after definitive treatment or at suspected relapse of CRC. Most often, this is done as a stand-alone procedure without ceCT, particularly in the restaging setting. Although some clinicians still request ceCT, which increases both cost and radiation burden. The incremental diagnostic value of this additional ceCT to FDG-PET/CT is unclear in this context and in several oncological settings. For example, in lymphoma, there are several studies that suggest the limited incremental benefit of ceCT (Freudenberg et al., 2004; Schaefer et al., 2004; Chalaye et al., 2014).

Therefore, our aim was to determine whether the addition of ceCT to FDG-PET/CT, when requested by the referring clinician for restaging of CRC patients, resulted in a change in the $\mathrm{N}$ or $\mathrm{M}$ stage of the patient and the implications of such changes for patient management according to institutional guidelines.

\section{Methods}

In accordance with the Declaration of Helsinki and as part of an institutional ethics-approved protocol (PMCC 02-51) investigating the impact of PET/CT on patient management, 385 consecutive CRC patients who were referred for PET/CT at a tertiary referral cancer hospital for staging, restaging or therapy response assessment over 9 months from Jan 2010 were retrospectively reviewed in this study. Patients who were imaged after neoadjuvant treatment were classified as restaging. Patients referred for staging were not included in the analysis. Of these, 91(24\%) had diagnostic contrast-enhanced CT scans; 86 encompassing chest to pelvis and 5 limited to coverage of all areas of PET/CT abnormality. All ceCT were performed within 8 weeks of PET/ CT scanning.

PET/CT studies were acquired on a Discovery 690 or STE (GE Medical Systems, Milwaukee, USA) or Biograph 64 with TruV (Siemens Medical Systems, USA). Activities based on patient weight $(285-370 \mathrm{MBq})$ were administered intravenously following a minimum of four-hour fast. The non-contrast CT scan parameters were helical mode acquisition, $140 \mathrm{kVp}, 80 \mathrm{mAs}$ and $3.27 \mathrm{~mm}$ slice thickness reconstruction. The FDG-PET scan parameters were same axial scan length as the CT scan (skull base to the proximal thighs), arms fully abducted unless limited by patient compliance, acquisition in 2-D or 3-D mode depending on the patient's weight (5-min acquisition time per bed position), iterative reconstruction using order-subset estimate maximisation 
algorithm. Images were reviewed using True-D software (Siemens), interpreted using qualitative criteria and reported as negative or positive for malignancy with further definition of local tumour, nodal and distant metastatic disease. Negative results were defined if no FDG uptake beyond normal physiological activity or mediastinal blood pool was identified, and positive if FDG uptake beyond normal physiological activity with the pattern of uptake suggestive of CRC. As per our usual clinical practice, semi-quantitative analysis of all PET-positive lesions was not routinely performed except when validating the qualitative impression of a partial metabolic response to therapy.

ceCT studies were acquired as dedicated CT scans on either a stand-alone or combined PET/CT system (Definition AS plus CT or Biograph 64 PET/CT, Siemens Medical Systems, USA). Patients fasted for a minimum of 4 hours, oral and intravenous contrast was administered using Omnipaque 300, $100 \mathrm{ml}$ (rate of $3 \mathrm{ml} / \mathrm{s}$ ). Apart from patients with limited scans, scans encompassed the lung apices to the pubic symphysis. CT scan acquisition parameters were helical mode, rotation time of $0.5 \mathrm{~s}$ using Care $\mathrm{kVp} / \mathrm{mAs}$ modulation and reconstructed slice thickness of $0.625 \mathrm{~mm}$. Images were reconstructed on lung and soft tissue windows, in axial and coronal planes, and reviewed on a Siemens PACS workstation.

FDG-PET/CT and ceCT reports were retrospectively assessed with $\mathrm{N}$ and $\mathrm{M}$ stage recorded based on the American Joint Committee on Cancer TNM staging system (7th edition) and compared. If discrepant, the medical notes were reviewed using composite end-points of histology, clinical follow-up, CT or PET/CT follow-up imaging to determine their nature. Management impact was determined following review of clinical notes and imaging findings by an experienced staff colorectal surgeon who retrospectively determined the management based on clinical setting and the PET/CT results, and further determined if the ceCT findings would have had any anticipated additional impact on management. The anticipated impact was categorised as no change, appropriate or inappropriate change in management according to institutional treatment guidelines.

Chi squared test was used to compare ratios with $p<0.05$ considered statistically significant. Kappa statistical agreement for $\mathrm{N}$ and $\mathrm{M}$ classification between PET/CT and ceCT was determined. Kappa scores were interpreted as $<0.00$ (poor agreement), $0.00-0.20$ (slight agreement), 0.21-0.40 (fair agreement), 0.41-0.60 (moderate agreement), 0.610.80 (substantial agreement), 0.81-1.00 (almost perfect agreement) (Landis et al., 1977).

\section{Results}

Of 91 patients, 8 patients were excluded for lack of sufficient follow-up to assess the validity of the imaging results. Of these 8 patients, $\mathrm{PET} / \mathrm{CT}$ and ceCT were concordant regarding $\mathrm{N}$ and $\mathrm{M}$ stage in 3 cases, PET/CT identified abnormalities not apparent on ceCT in 2 cases, ceCT detected additional abnormalities not seen on PET/CT in 3 cases. While these 5 patients with discordant imaging findings may have affected the results, we feel that the effect is likely to be minimal due to the small and similar number of these patients present in each discordant group. A further patient (discussed below) was excluded from the statistical analysis as PET/CT showed a lung lesion that was subsequently demonstrated to be a primary lung cancer rather than metastatic CRC. 
Of the remaining 82 patients, 8 studies were performed for initial staging (and excluded from analysis) and 74 for restaging. The median age of the patients was 62 (3388) years. There were 46 males and 28 females (M:F ratio 1.64:1). The ceCT scan was performed prior to, or on the same day as the PET scan in 69 (93\%) patients (21 and 48 cases respectively). Of the 74 patients, $\mathrm{N}$ and $\mathrm{M}$ stages on PET/CT and ceCT were concordant in 56 patients (76\%). Of the 18 discordant cases, follow-up clarification occurred over a median period of 3 months ( $0-16$ months) and the true or false positivity of the discordant findings were clarified based on follow-up in the following respective cases: histology ( 8 cases), ceCT (1 case), MRI ( 2 cases), PET/CT (5 cases), clinical review ( 2 cases). However, PET/CT identified incremental abnormalities in 9 cases with 6 apparently true positive and 3 false positive (Tables 1 and 2, respectively) while ceCT found incremental abnormalities in 9 cases with 4 apparently true positive and 5 false positive (Tables 3 and 4, respectively). Thus, overall, 91\% (67/74) patients would have been correctly evaluated by PET/CT without reference to the ceCT. Had the true positive incremental PET/CT findings in Table 1 been ignored in favour of the negative ceCT findings, it would have led to inappropriate management in 5/6 patients whereas in those with incremental findings on ceCT (Tables 3 and 4), inappropriate and appropriate management changes would have been anticipated in 1 and 2 patients respectively. Thus, ceCT did not provide any net incremental benefit in selecting appropriate management compared to the PET/CT findings alone. When comparing PET/CT and ceCT, kappa agreement (95\% confidence interval) for $\mathrm{N}$ and $\mathrm{M}$ stage was 0.58 (0.20$0.95)$ and $0.60(0.41-0.79)$ respectively reflecting moderate agreement.

\section{Discussion}

Non-invasive imaging plays a critical role in the staging and especially, restaging of patients with CRC. This role was initially and is still frequently assigned to ceCT. However, with the advent of FDG-PET and subsequent PET/CT, these patients are increasingly evaluated with this modality preferentially. Nevertheless, a proportion of

Table 1 Summarised ceCT results in discordant cases with incremental PET/CT abnormalities that were likely true positive

\begin{tabular}{lllll}
\hline Case & PET/CT finding & ceCT finding & Followup & Anticipated impact of \\
ceCT on management
\end{tabular}


Table 2 Summarised ceCT results in discordant cases with incremental PET/CT abnormalities that were likely false positive

\begin{tabular}{|c|c|c|c|c|}
\hline Case & PET/CT finding & ceCT finding & Followup & $\begin{array}{l}\text { Anticipated impact } \\
\text { of ceCT on } \\
\text { management }\end{array}$ \\
\hline 2.1 & $\begin{array}{l}\text { N2 locoregional nodal minimal } \\
\text { FDG uptake and M1 distant } \\
\text { nodal FDG uptake }\end{array}$ & $\begin{array}{l}\text { Locoregional } \\
\text { and distant } \\
\text { nodes up to } \\
\text { max } 10 \mathrm{~mm} \text {. }\end{array}$ & $\begin{array}{l}\text { Locoregional nodes excised, } \\
\text { negative for metastases but } \\
\text { performed } 2 \text { months after PET and } \\
\text { in context of marked pathological } \\
\text { response in previously bulky } \\
\text { primary }\end{array}$ & No change \\
\hline 2.2 & $\begin{array}{l}\text { Minimal residual uptake in one } \\
\text { lesion with resolution of other } \\
\text { liver lesions }\end{array}$ & No liver lesions & $\begin{array}{l}\text { In context of marked regression of } \\
\text { prior multifocal disease likely } \\
\text { reflected minimal residual disease. } \\
\text { Repeat PET/CT } 5 \text { months later: no } \\
\text { FDG avid liver lesions }\end{array}$ & No change \\
\hline 2.3 & $\begin{array}{l}\text { FDG avid lung lesion thought } \\
\text { malignant and axillary nodal } \\
\text { lesion thought equivocal for } \\
\text { metastasis or inflammation }\end{array}$ & $\begin{array}{l}\text { Lung lesion, no } \\
\text { axillary nodal } \\
\text { lesion seen }\end{array}$ & $\begin{array}{l}\text { Following excision: Lung lesion } \\
\text { positive for metastasis, axillary } \\
\text { lesion was reactive }\end{array}$ & No change \\
\hline
\end{tabular}

patients still have both studies with consequent increase in radiation exposure, overall healthcare cost, as well as the logistic inconvenience of attending both episodes unless done as part of a combined procedure. In our facility, only $24 \%$ of all patients referred for an FDG-PET/CT had ceCT requested by their managing clinician.

In those patients in whom ceCT was requested, no incremental information was provided in 76\% (56/74). Further, 91\% (67/74) patients would have been correctly evaluated by PET/CT without reference to the ceCT. There were 4 (5\%) cases (Tables 3, 4 cases including 2 cases who had neoadjuvant chemotherapy were for restaging) where $\mathrm{PET} / \mathrm{CT}$ was false negative at a site of residual structural abnormality on ceCT. All involved PET/CT scans were performed early after neoadjuvant chemotherapy (Table 3, cases 2.3 and 2.4) or chemoradiotherapy (Table 3, cases 2.1 and 2.2) and indicated a complete metabolic response. We have demonstrated that a complete metabolic

Table 3 Summarised ceCT results in discordant cases with incremental ceCT abnormalities that were likely true positive

\begin{tabular}{|c|c|c|c|c|}
\hline Case & PET/CT finding & ceCT finding & Followup & $\begin{array}{l}\text { Anticipated impact } \\
\text { of ceCT on } \\
\text { management }\end{array}$ \\
\hline 3.1 & $\begin{array}{l}\text { Complete metabolic } \\
\text { response in liver } \\
\text { metastases } 2 \text { weeks post- } 6 \\
\text { cycles of chemotherapy }\end{array}$ & $\begin{array}{l}\text { Improved but } \\
\text { persistent liver } \\
\text { lesions (largest } \\
13 \mathrm{~mm} \text { ) }\end{array}$ & $\begin{array}{l}\text { True positive. } \\
\text { (Small volume residual viable } \\
\text { tumour in hepatic resection) }\end{array}$ & No change \\
\hline 3.2 & $\begin{array}{l}\text { No abnormal FDG uptake in } \\
\text { peripancreatic nodal mass }\end{array}$ & $\begin{array}{l}\text { Peripancreatic } \\
\text { mass }(37 \mathrm{~mm})\end{array}$ & $\begin{array}{l}\text { Repeat PET } 2 \text { months later, } \\
\text { peripancreatic nodal mass } \\
\text { became FDG avid. } \\
\text { (Original PET performed } \\
1 \text { month post completion } \\
\text { of chemoradiotherapy) }\end{array}$ & $\begin{array}{l}\text { Appropriate } \\
\text { change }\end{array}$ \\
\hline 3.3 & No abnormal FDG uptake & $\begin{array}{l}\text { Locoregional } \\
\text { nodal disease } \\
\text { (N1) }\end{array}$ & $\begin{array}{l}\text { Histology of resected primary showed } \\
\text { locoregional nodal disease (PET } \\
\text { performed post neoadjuvant } \\
\text { chemotherapy). }\end{array}$ & No change \\
\hline 3.4 & No metastases & $\begin{array}{l}\text { Locoregional } \\
\text { nodal disease } \\
\text { (N1) }\end{array}$ & $\begin{array}{l}\text { Nodes positive for metastases on } \\
\text { primary excision specimen. (PET } \\
\text { performed post neoadjuvant } \\
\text { chemoradiotherapy) }\end{array}$ & No change \\
\hline
\end{tabular}


Table 4 Summarised ceCT results in discordant cases with incremental ceCT abnormalities that were likely false positive

\begin{tabular}{|c|c|c|c|c|}
\hline Case & PET/CT finding & ceCT finding & Followup & $\begin{array}{l}\text { Anticipated impact of } \\
\text { ceCT on management }\end{array}$ \\
\hline 4.1 & No metastases & Liver metastasis & $\begin{array}{l}\text { Post-chemotherapy scans. } \\
\text { Microwave ablation to liver } \\
\text { after scans. Followup PET } 13 \\
\text { months later: negative for } \\
\text { metastases. Clinical follow up } \\
3 \text { years later: well }\end{array}$ & Appropriate change $^{a}$ \\
\hline $\begin{array}{l}4.2 \\
\text { (Fig. 2) }\end{array}$ & No metastases & $\begin{array}{l}\text { Necrotic right external } \\
\text { iliac nodes: Interval } \\
\text { decrease in size }\end{array}$ & $\begin{array}{l}\text { Post-chemoradiotherapy. } \\
\text { Following excision: nodes } \\
\text { negative for metastasis. }\end{array}$ & Inappropriate change \\
\hline 4.3 & No metastases & $\begin{array}{l}\text { Left paraaortic node } \\
\text { suspicious for metastasis }\end{array}$ & $\begin{array}{l}\text { Repeat CT } 39 \text { months later: } \\
\text { node stable in size, CEA } \\
\text { undetectable }\end{array}$ & No change \\
\hline 4.4 & No metastases & $\begin{array}{l}\text { Left upper quadrant } \\
\text { omental deposit }\end{array}$ & $\begin{array}{l}\text { Clinical follow up } 1.5 \text { months } \\
\text { later: no evidence of } \\
\text { metastases }\end{array}$ & No change \\
\hline 4.5 & No metastases & $\begin{array}{l}\text { Equivocal change in } \\
\text { known penile metastasis }\end{array}$ & $\begin{array}{l}\text { MRI showed improvement in } \\
\text { penile metastasis }\end{array}$ & No change \\
\hline
\end{tabular}

${ }^{\text {a }}$ confirmed by histology

response (CMR) in this setting is associated with an excellent prognosis (Kalff et al., 2006; Yeung et al., 2011). In our surgical oncology practice, surgery after neoadjuvant treatment is planned on the basis of baseline staging, including MRI of the primary, if rectal, and liver. In this context, restaging FDG-PET/CT is performed prior to resection of the primary or limited metastatic disease purely to exclude chemorefractory disease or progression of disease beyond the prior sites of involvement, particularly at extra-hepatic sites, which would, in most cases, preclude attempted curative surgery and significantly alter the surgical approach. Accordingly, the presence of residual ceCT abnormality in the context of a CMR has little or no impact on management in our centre. Indeed, in only 1 case was active management delayed by a false-negative FDG-PET/CT result. In this case, follow-up FDG-PET/CT confirmed recrudescent disease in residual peri-pancreatic nodes. In the remaining cases, only microscopic residual disease was identified. It is actually unlikely that ceCT identified these foci but rather the presence of residual morophological abnormality related to regressing

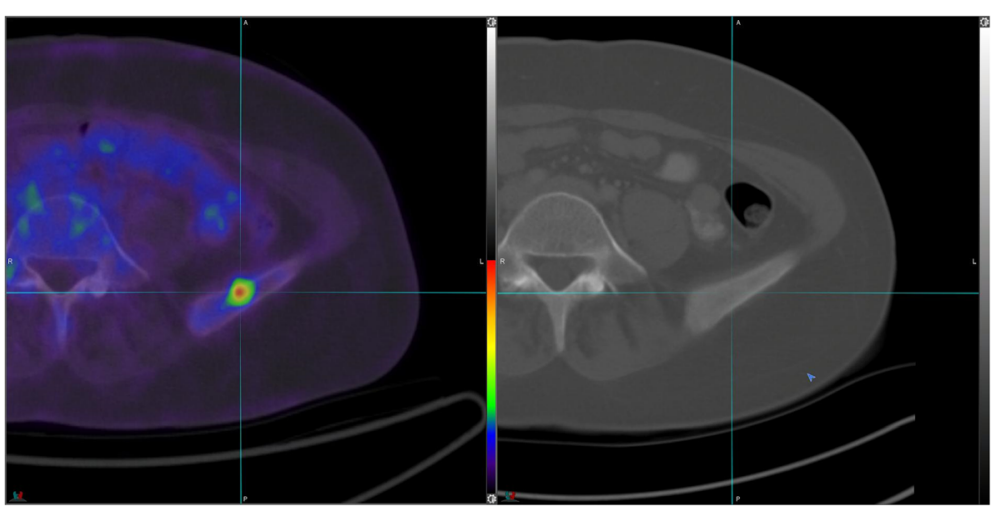

Fig. 1 Case 1.1 - Example of discordant case where PET appropriately changed management. FDG avid bone metastasis in left iliac bone (left panel) not seen on diagnostic CT (right panel) 


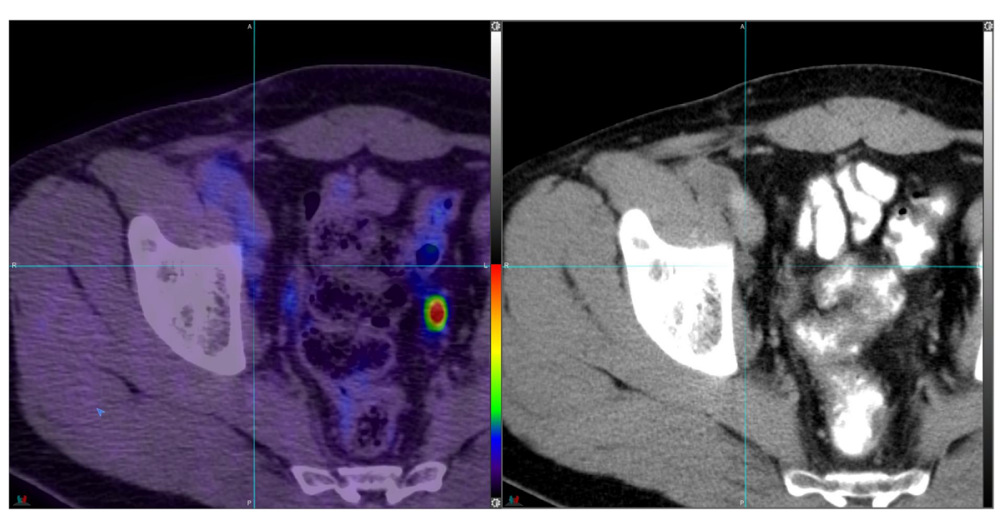

Fig. 2 Case 4.2. Example of discordant case where CT led to inappropriate treatment. Right external iliac nodes on diagnostic CT (right panel) which show no FDG uptake on PET (left panel). More extensive resection performed of presumed nodal disease, which was negative for metastasis

metastases. Conversely, 5 out of 6 cases with incremental abnormalities on PET/CT compared to ceCT, the FDG study had a significant management impact, including 4 cases of unrecognised distant metastatic disease and 1 case of pelvic nodal metastatic disease. There were, however, 3 patients where the PET/CT findings suggested residual or metastatic disease that were negative on $\mathrm{ceCT}$ and which were subsequently demonstrated to be true negative on follow-up. These lesions had minimal FDG uptake and were thought to be of equivocal significance rather than unequivocally positive on $\mathrm{PET} / \mathrm{CT}$ as the prior PET/CT were significantly positive in these areas for 2 of these cases. In these 3 patients, the addition of ceCT was also not anticipated to result in a change in management. In contrast, there were 4 that were thought to have distant metastases on ceCT that were true negative on FDG-PET/CT, and if PET/CT had not been performed in these patients, inappropriate management could have resulted. PET/ $\mathrm{CT}$ also detected an incidental lung cancer in another patient excluded from analysis.

When comparing these findings to the available literature, there are limited similar studies available to date. The evolution of PET with the addition of non-contrast CT significantly increases the overall accuracy of the modality in the evaluation of a variety of malignancies including CRC (Kamel et al., 2004; Engledow et al., 2009). In our study, additional disease was correctly identified by PET/CT in $8 \%(6 / 74)$ of patients. This rate is slightly lower than a study by Kong et al. (Kong et al., 2008), which compared $\mathrm{PET} / \mathrm{CT}$ with $\mathrm{ceCT}$ in patients with suspected but potentially operable CRC liver metastases. In their study, PET/CT demonstrated unexpected extrahepatic disease in $17 \%$ $(11 / 65)$ of patients resulting in management change. The lower rate of incremental $\mathrm{PET} / \mathrm{CT}$ findings in our series may reflect the timing of scans relative to chemotherapy with several of our false negative studies based on pathology representing post-treatment scans that failed, as expected, to detect residual microscopic disease.

The incremental value of the ceCT, thus, possibly does not justify the additional radiation exposure and potential toxicity of contrast administration. Hence in patients who are unable to undergo contrast administration due to renal impairment or iodine allergy, these patients may be adequately assessed by PET/CT as our data suggests that routine additional ceCT assessment probably provides no significant incremental benefit beyond PET/CT assessment. Moulton et al. (Moulton et al., 2014) demonstrated that 
in CRC patients with potentially resectable metastatic disease, the use of PET/CT resulted in an $8.0 \%$ change in surgical management compared to patients who had CT alone. In that study, of the patients who were randomised to and received PET/CT imaging, $58 \%$ of the PET/CT results were concordant with ceCT findings. In contrast, $76 \%$ of patients in this study were concordant. Some of this difference may relate to the population assessed by Moulton et al. being mainly assessed at primary staging whereas our study predominantly involved therapeutic response or restaging studies. Nevertheless, the findings by Moulton et al. would support our conclusion that performing both ceCT and PET/CT in the same patient would seem unwarranted. Our findings suggest that imaging with PET/CT alone is probably the preferred single modality and that there is probably minimal or no additional clinical benefit of undergoing a diagnostic CT if a PET/CT has already been performed.

In this study, the only situation in which ceCT appeared to provide more information than PET/CT, was in the assessment of regional nodal status in the post neo-adjuvant treatment setting. However, detection of nodes in this setting has no significant impact on planned surgery or subsequent patient management. In general, locoregional nodal assessment by MRI rather than ceCT is probably the better (Kim et al., 2000; Al-Sukhni et al., 2012; Dewhurst et al., 2012; Glynne-Jones et al., 2014) and preferred imaging modality in the setting of primary staging of rectal cancer (Brown et al., 2003) and possibly also for colorectal malignancy.

\section{Limitations}

This retrospective analysis reflects routine clinical practice within a facility in which there is large experience amongst referring and imaging specialists in using FDG-PET/ $\mathrm{CT}$ in CRC. The majority of the patients were imaged for restaging with only a minority of patients referred for ceCT, there is potential for pre-test selection bias that may have influenced its apparent performance in the group who were. However, it would be expected that such a bias would be towards referring patients with a high pre-test likelihood of disease, which would diminish the incremental value of PET-CT.

As the readers of each modality at the time of clinical reporting were not blinded to the results from the other modality this might have biased the degree of concordance between the 2 modalities. However, correlation of findings between modalities is reflective of best practice in today's current multimodality cancer imaging environment.

As some of the ceCT was performed after PET/CT, there may have been potentially some post-test referral bias. While the exact timing of when each modality was requested compared to the other is not available, it is noted however that as the date of the ceCT was performed a day or greater after PET/CT in only $7 \%(5 / 74)$ of the cases, this bias, if any, is presumed to be small.

Management change was determined retrospectively, which may have biased results. However, it is not difficult to determine management change as treatment pathways for CRC are well established in our institution.

Histological correlation to confirm malignant or benign disease was not performed in all patients and in some patients follow-up was based on a repeat FDG-PET/CT scan, which may have led to an ascertainment bias in the results. While pathology is considered the gold standard, follow-up imaging may provide sufficient evidence in the 
appropriate clinical circumstance, the pattern of progressive metabolically active lesions is highly likely to reflect progressive metastases. Conversely, in 5 patients, where there had false positive ceCT findings, additional pathological correlation beyond surgery that was already planned was only performed in 1 patient. Treating units are often reluctant to subject these patients to invasive investigations to histologically confirm benignancy in ceCT-identified but metabolically-inactive lesions.

While not specifically examined in this study, newer PET/CT cameras are able to acquire PET with co-registered $\mathrm{CT}$ at essentially diagnostic quality with substantially reduced radiation doses.

\section{Conclusion}

In evaluating patients with CRC, our data indicate that whole body diagnostic CT may possibly be omitted in patient who are also undergoing PET/CT, as it provides probably no significant incremental value in treatment selection. However, to obtain comprehensive and accurate imaging information, we would still consider supplementing whole body PET/CT with targeted regional imaging with MRI (Kim et al., 2011) or contrast-enhanced CT based on clinical circumstances, suspicion or when high resolution anatomical information is required for targeted investigation, to resolve equivocal FDG-PET/CT abnormalities (Hicks et al., 2006), treatment planning or response assessment. We believe this to be an efficient use of the complementary strengths of each modality.

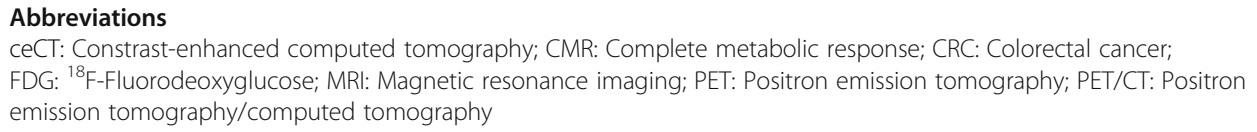

All authors have made substantial contributions to the work including contributions to conception and design, or acquisition of data, or analysis and interpretation of data; and drafting or revising the work critically for intellectual content; and approve this version to be published; and agree to be accountable for all aspects of the work in ensuring that questions related to the accuracy or integrity of any part of the work are appropriately investigated and resolved.

\section{Ethics approval and consent to participate}

All procedures performed in studies were in accordance with the ethical standards of the institutional (Peter MacCallum Cancer Centre) research committee (ethics-approved protocol number: PMCC 02-51) and with the 1964 Helsinki declaration and its later amendments or comparable ethical standards.

As this is a low risk retrospective study, formal subject consent is not required and an ethics waiver from obtaining informed consent from individual patients was sought and approved.

\section{Consent for publication}

Manuscript images are entirely unidentifiable and there are no details on individuals reported within the manuscript hence consent for publication of images was not sought. 


\section{Publisher's Note}

Springer Nature remains neutral with regard to jurisdictional claims in published maps and institutional affiliations.

\section{Author details}

'Department of Nuclear Medicine and PET, Level 1, East Block, The Alfred Hospital, Commercial Road, Melbourne, VIC 3004, Australia. ${ }^{2}$ Cancer Imaging, Peter MacCallum Cancer Institute, Melbourne, Australia. ${ }^{3}$ Department of Surgical Oncology, Peter MacCallum Cancer Institute, Melbourne, Australia. ${ }^{4}$ Department of General Medicine, Melbourne Health, Melbourne, Australia. ${ }^{5}$ Molecular Imaging \& Therapy and Department of Radiology, Austin Health, Melbourne, Australia. ${ }^{6}$ Department of Radiology, University of Melbourne, Melbourne, Australia. ${ }^{7}$ Sir Peter MacCallum Department of Oncology, University of Melbourne, Melbourne, Australia.

\section{Received: 24 June 2018 Accepted: 7 November 2018}

\section{Published online: 26 November 2018}

\section{References}

Al-Sukhni E, Milot L, Fruitman M, Beyene J, Victor JC, Schmocker S et al (2012) Diagnostic accuracy of MRI for assessment of T category, lymph node metastases, and circumferential resection margin involvement in patients with rectal cancer: a systematic review and meta-analysis. Ann Surg Oncol 19:2212-2223. https://doi.org/10.1245/s10434-011-2210-5

Brown G, Radcliffe AG, Newcombe RG, Dallimore NS, Bourne MW, Williams GT (2003) Preoperative assessment of prognostic factors in rectal cancer using high-resolution magnetic resonance imaging. Br J Surg 90:355-364. https://doi.org/10.1002/ bjs. 4034

Chalaye J, Luciani A, Enache C, Beaussart P, Lhermite C, Evangelista E, et al. (2014) Clinical impact of contrast-enhanced computed tomography combined with low-dose F-fluorodeoxyglucose positron emission tomography/computed tomography on routine lymphoma patient management. Leuk lymphoma. doi:https://doi.org/10.3109/10428194.2014. 900761

Davey K, Heriot AG, Mackay J, Drummond E, Hogg A, Ngan S et al (2008) The impact of 18-fluorodeoxyglucose positron emission tomography-computed tomography on the staging and management of primary rectal cancer. Dis Colon rectum 51:997-1003. https://doi.org/10.1007/s10350-008-9244-1

Dewhurst C, Rosen MP, Blake MA, Baker ME, Cash BD, Fidler JL et al (2012) ACR appropriateness criteria pretreatment staging of colorectal cancer. J Am Coll Radiol 9:775-781. https://doi.org/10.1016/j.jacr.2012.07.025

Engledow AH, Bond-Smith GE, Francis D, Pakzad F, Bomanji J, Groves A et al (2009) The incremental value of dual modality PET/CT imaging over PET imaging alone in advanced colorectal cancer. Indian J Surg 71:63-68. https://doi.org/10.1007/ s12262-009-0018-3

Freudenberg LS, Antoch G, Schutt P, Beyer T, Jentzen W, Muller SP et al (2004) FDG-PET/CT in re-staging of patients with lymphoma. Eur J Nucl Med Mol Imaging 31:325-329. https://doi.org/10.1007/s00259-003-1375-y

Gambhir SS, Czernin J, Schwimmer J, Silverman DH, Coleman RE, Phelps ME (2001) A tabulated summary of the FDG PET literature. J Nucl Med 42:15-93S

Glynne-Jones R, Tan D, Goh V (2014) Pelvic MRl for guiding treatment decisions in rectal cancer. Oncology (Williston Park) 28: 667-677

Hicks RJ, Ware RE, Lau EW (2006) PET/CT: will it change the way that we use CT in cancer imaging? Cancer Imaging 6:S52S62. https://doi.org/10.1102/1470-7330.2006.9012

Kalff V, Duong C, Drummond EG, Matthews JP, Hicks RJ (2006) Findings on 18F-FDG PET scans after neoadjuvant chemoradiation provides prognostic stratification in patients with locally advanced rectal carcinoma subsequently treated by radical surgery. J Nucl Med 47:14-22

Kamel IR, Cohade C, Neyman E, Fishman EK, Wahl RL (2004) Incremental value of CT in PET/CT of patients with colorectal carcinoma. Abdom Imaging 29:663-668. https://doi.org/10.1007/s00261-003-0163-2

Kim DJ, Kim JH, Ryu YH, Jeon TJ, Yu JS, Chung JJ (2011) Nodal staging of rectal cancer: high-resolution pelvic MRI versus 18FFDGPET/CT. J Comput Assist Tomogr 35:531-534. https://doi.org/10.1097/RCT.0b013e318225720f

Kim NK, Kim MJ, Park JK, Park SI, Min JS (2000) Preoperative staging of rectal cancer with MRI: accuracy and clinical usefulness. Ann Surg Oncol 7:732-737

Kong G, Jackson C, Koh DM, Lewington V, Sharma B, Brown G et al (2008) The use of 18F-FDG PET/CT in colorectal liver metastases--comparison with CT and liver MRI. Eur J Nucl Med Mol Imaging 35:1323-1329. https://doi.org/10.1007/ s00259-008-0743-z

Landis JR, Koch GG (1977) The measurement of observer agreement for categorical data. Biometrics 33:159-174

Moulton CA, Gu CS, Law CH, Tandan VR, Hart R, Quan D et al (2014) Effect of PET before liver resection on surgical management for colorectal adenocarcinoma metastases: a randomized clinical trial. Jama 311:1863-1869. https:/doi.org/ 10.1001/jama.2014.3740

Schaefer NG, Hany TF, Taverna C, Seifert B, Stumpe KD, von Schulthess GK et al (2004) Non-Hodgkin lymphoma and Hodgkin disease: coregistered FDG PET and CT at staging and restaging--do we need contrast-enhanced CT? Radiology 232:823829. https://doi.org/10.1148/radiol.2323030985

Yeung JM, Kalff V, Hicks RJ, Drummond E, Link E, Taouk Y et al (2011) Metabolic response of rectal cancer assessed by 18FDG PET following chemoradiotherapy is prognostic for patient outcome. Dis Colon rectum 54:518-525. https://doi.org/ 10.1007/DCR.0b013e31820b36fo 